\title{
Fisiologia pós-colheita de frutos da palmeira Syagrus oleracea (Mart.) Becc. (Arecaceae) $^{1}$
}

\author{
Paulo Santelli ${ }^{2}$, Maria Elisa Ribeiro Calbo ${ }^{2,4}$ e Adonai Gimenez Calbo ${ }^{3}$
}

Recebido em 22/06/2005. Aceito em 3/01/2006

\begin{abstract}
RESUMO - (Fisiologia pós-colheita de frutos da palmeira Syagrus oleracea (Mart.) Becc. (Arecaceae)). Objetivou-se avaliar algumas das mudanças fisiológicas ocorridas durante o processo de amadurecimento pós-colheita dos frutos de Syagrus oleracea (gueroba), palmeira nativa da região Centro-Oeste brasileira, tais como: a perda de massa, volumes gasosos intercelulares, a concentração interna de $\mathrm{CO}_{2}$ e de $\mathrm{O}_{2}$ e a firmeza, as evoluções de $\mathrm{CO}_{2}$ e etileno tanto à temperatura ambiente $\left(25^{\circ} \mathrm{C}\right)$ quanto à baixa temperatura $\left(8^{\circ} \mathrm{C}\right)$. Para as análises foram utilizados frutos verdes desta palmeira, coletados no campus da Universidade de Brasília (UnB). Os frutos da gueroba se mostraram sensíveis à injúria por resfriamento. Quando armazenados à temperatura de $8^{\circ} \mathrm{C}$, apresentaram sinais de injúria pelo frio e não amadureceram mesmo quando foram recolocados à temperatura ambiente $\left(25^{\circ} \mathrm{C}\right)$. A ocorrência de pico de evolução de etileno e $\mathrm{CO}_{2}$ coincidente, no mesmo dia, e os padrões das curvas de concentração de $\mathrm{CO}_{2}$ e $\mathrm{O}_{2}$ na atmosfera interna com pico são evidências de que se trata de um fruto climatérico, bem como o fato da produção de etileno ter aumentado 12 vezes entre o verde-maduro e o pico. $\mathrm{O}$ valor obtido para os volumes gasosos intercelulares da gueroba coloca os seus frutos dentro da faixa de órgãos com média quantidade de volumes gasosos, média susceptibilidade à injúria de impacto e média susceptibilidade as injúrias de amassamento.
\end{abstract}

Palavras-chave: amadurecimento, atmosfera interna, climatério, volumes gasosos intercelulares

\begin{abstract}
Post-harvest physiology of palm fruits of Syagrus oleracea (Mart.) Becc. (Arecaceae)). Several aspects of post-harvest changes in fruits of a native palm species from the Central Plateau in mid-western Brazil were studied. Fruits of Syagrus oleracea (Mart.) Becc., commonly known as "gueroba", were evaluated regarding aspects such as: weight loss, internal gaseous volume, internal concentration of $\mathrm{CO}_{2}$ and $\mathrm{O}_{2}$, firmness, chilling injury and $\mathrm{CO}_{2}$ and ethylene evolution. Fruits of S. oleracea are sensitive to chilling injury when stored at low temperatures such as $8{ }^{\circ} \mathrm{C}$ where they failed to ripen after storage. The occurrence of a simultaneous climateric peak for $\mathrm{CO}_{2}$ and ethylene plus the internal $\mathrm{CO}_{2}$ and $\mathrm{O}_{2}$ concentration patterns are strong evidence that this is a climateric fruit. The gaseous intercellular volumes obtained for $S$. oleracea fruits place them together with other organs that have medium quantity of these volumes, which means that this fruit may have medium susceptibility to impact injury and medium susceptibility to injury by compression.
\end{abstract}

Key words: chilling injury, climateric, internal atmosphere, ripening

\section{Introdução}

As espécies da família Arecaceae, plantas conhecidas como palmeiras, apresentam grande importância econômica e são exploradas comercialmente na produção de óleo, amido, palmito, cera e fibras. São também utilizadas como fonte de alimentos, bebidas e como matéria-prima para construção de barcos, pontes e casas. As plantas são utilizadas na ornamentação de praças, jardins e ambientes internos há vários séculos. As palmeiras são de ocorrência predominantemente tropical (Henderson et al. 1995), têm a capacidade de se estabelecer em diversos tipos de hábitat, como mata de terra firme, matas periodicamente inundadas, cerrado, e em ambientes degradados. No Brasil encontram-se extensamente distribuídas (Lorenzi et al. 2004).

A realização de estudos fisiológicos é fundamental para o conhecimento da ecofisiologia dessa família e pode, ainda, contribuir para a preservação e propagação de suas espécies. Foi então selecionada uma espécie muito comum no Distrito Federal (DF), Syagrus oleracea (Mart.) Becc., para estudos fisiológicos de seus frutos.

A palmeira Syagrus oleracea (Mart.) Becc., popularmente conhecida como gueroba, é comum nos campos sujos de cerrado. Ocorre nos estados de São Paulo, Minas Gerais, Mato Grosso, Goiás, Mato Grosso do Sul, Bahia e no Distrito Federal (Lorenzi 1992). O gênero Syagrus é um dos três mais freqüentes em

\footnotetext{
1 Parte da Dissertação de Mestrado do primeiro Autor

2 Universidade de Brasília, Departamento de Botânica, Laboratório de Fisiologia Vegetal, C. Postal 04457, 70910-970 Brasília, DF, Brasil

3 EMBRAPA Hortaliças, Laboratório de Pós-colheita, C. Postal 218, 70359-970 Brasília, DF, Brasil

4 Autor para correspondência: mecalbo@unb.br
} 
número de espécies de palmeiras no Brasil, e o de maior representatividade na região do Cerrado (Henderson et al. 1995). A gueroba é uma palmeira de tronco simples, com folhas perenes, dispostas em forma de espiral e levemente arqueadas. Os frutos são ovalados e possuem cerca de 6 a $7 \mathrm{~cm}$ de comprimento e sua coloração externa é verdeamarelada. Os frutos possuem polpa fibrosa amarelada quando madura, contendo amêndoa sólida, dura, branca e oleaginosa, são comestíveis e de sabor agradável e servem de alimento também à fauna. A gueroba é uma palmeira muito ornamental, apresentando bom potencial para o uso em paisagismo. Seu cultivo é fácil porque é pouco exigente quanto à fertilidade do solo (Correa 1931; Henderson et al. 1995; Lorenzi 2004).

Para frutos nativos do cerrado, existem poucos trabalhos em que se tenha avaliado a respiração e a evolução de etileno. Dentre estes, podem ser citados os estudo da cagaita (Eugenia dysenterica) (Calbo et al. 1990) e do pequi (Caryocar brasiliense) (Calbo \& Miranda 1991). A carência é maior ainda para os frutos das palmeiras brasileiras que precisam ser ainda estudados quanto à respiração e à evolução de etileno e ao seu comportamento em ambientes de armazenamento.

Este trabalho foi desenvolvido para ampliar o conhecimento da fisiologia e do comportamento póscolheita dos frutos de Syagrus oleracea. Para este fim, foi estudada a evolução de $\mathrm{CO}_{2}$ e etileno em duas temperaturas; foi acompanhada a composição da atmosfera interna dos frutos; foram quantificados os volumes gasosos intercelulares e foi acompanhada a firmeza dos frutos durante o amadurecimento.

\section{Material e métodos}

Foram colhidos frutos maturos, com desenvolvimento máximo. Para a determinação da maturidade dos frutos, foi considerado o aspecto visual dos frutos a serem coletados. Coletaram-se frutos que já possuíam pequenas rajadas amarelas.

Os frutos da Syagrus oleracea (Mart.) Becc. (gueroba) foram coletados no campus da UnB $\left(15^{\circ} 45,987^{\prime} \mathrm{S}\right.$ e $\left.47^{\circ} 52,066^{\prime} \mathrm{W}\right)$ e transportados, seja para o laboratório de Fisiologia Vegetal do Departamento de Botânica da UnB, seja para o Laboratório de PósColheita da Embrapa Hortaliças. Houve cuidado para não expô-los à elevada temperatura e luz solar direta durante o trajeto, bem como à ventilação excessiva. Os frutos foram selecionados quanto à homogeneidade de cor e tamanho.
Cromatografia - Para medidas de evolução de etileno e $\mathrm{CO}_{2}$, os tratamentos avaliados foram $8{ }^{\circ} \mathrm{C} \pm 3{ }^{\circ} \mathrm{C}$ e $25{ }^{\circ} \mathrm{C} \pm 3{ }^{\circ} \mathrm{C}$ de temperatura para frutos armazenados em conjunto; foram feitas seis repetições por tratamento e cada repetição continha seis frutos. Foi feito também um estudo com frutos individuais, com seis repetições. Este último tratamento com frutos individuais foi feito para evitar que caso houvesse a evolução de etileno de frutos amadurecidos precocemente esta não viesse a antecipar o amadurecimento dos demais frutos, caso os frutos fossem climatéricos.

A evolução de $\mathrm{CO}_{2}$ e etileno foi avaliada em um sistema fechado, no qual os frutos em conjunto foram colocados em frascos de $1.350 \mathrm{ml}$ e os frutos individuais em frascos de $131 \mathrm{ml}$. Amostras de $1 \mathrm{~cm}^{3}$ foram extraídas com seringa hipodérmica graduada, e injetadas em cromatógrafo a gás Finnigan modelo 9001, equipado com uma coluna "poropak N" e uma coluna de exclusão molecular. Foi usado o gás hidrogênio como gás de arraste a um fluxo de $30 \mathrm{ml} \mathrm{min}^{-1}$ para as medições das concentrações de $\mathrm{CO}_{2}$ e etileno.

Os frutos foram pesados diariamente após a realização das medições para acompanhar a perda de massa em cada uma das repetições.

Atmosfera interna - Para acompanhar a evolução da concentração de $\mathrm{O}_{2}$ e $\mathrm{CO}_{2}$ na atmosfera interna dos frutos armazenados a $25^{\circ} \mathrm{C}$, foram utilizados a câmara externa de Devaux, para a retirada de amostras da atmosfera interna, e o método FACILI (Calbo 2004) para a sua quantificação. A câmara externa de Devaux é uma técnica de equilíbrio difusivo, baseada na obtenção de um equilíbrio gasoso dinâmico, por difusão, entre o volume da câmara e a atmosfera interna do órgão (A.C. Cameron, dados não publicados). Foram feitas coletas diariamente de amostras com 0,1 a $0,5 \mathrm{ml}$ e estas amostras foram analisadas no FACILI. Após a injeção da amostra gasosa, foi medido o seu volume inicial $\left(\mathrm{V}_{1}\right)$, seguido do volume gasoso remanescente após a captura do $\mathrm{CO}_{2}$ em $\mathrm{NaOH}\left(\mathrm{V}_{2}\right)$ e, finalmente, foi medido o volume gasoso remanescente após a captura do $\mathrm{O}_{2}$ em pirogalol $\left(\mathrm{V}_{3}\right)$. Com esses dados foram calculadas as porcentagens de $\mathrm{CO}_{2}$ e de $\mathrm{O}_{2}: \%$ $\mathrm{CO}_{2}=100 .\left(\mathrm{V}_{1}-\mathrm{V}_{2}\right) / \mathrm{V}_{1}$ e $\% \mathrm{O}_{2}=100 .\left(\mathrm{V}_{2}-\mathrm{V}_{3}\right) / \mathrm{V}_{1}$.

Constante de conversão (r) - Foi calculada como a razão entre a concentração de $\mathrm{CO}_{2}$ da atmosfera interna (ci) contida nos espaços intercelulares em $\mathrm{ml} \mathrm{L}^{-1}$, obtida nas medidas com o FACILI, e a taxa de evolução de $\mathrm{CO}_{2}(\mathrm{R}) \mathrm{em} \mathrm{ml} \mathrm{kg}{ }^{-1} \mathrm{~h}^{-1}$, obtida na medida de $\mathrm{CO}_{2}$ no cromatógrafo. $\mathrm{r}=\mathrm{ci} / \mathrm{R}$ 
Com essa constante pode-se estimar a concentração interna de $\mathrm{CO}_{2}$, sabendo-se a taxa de evolução $\mathrm{CO}_{2}$, ou pode-se calcular a taxa de respiração, conhecendo-se a concentração da atmosfera interna. A constante de conversão também é denominada de resistência difusiva do órgão vegetal.

Volumes gasosos intercelulares - O método utilizado para as medidas de porosidade ou a quantificação dos volumes gasosos intercelulares foi o de Jensen et al. (1969) com modificações. Nesse método, denominado picnométrico, a fração de espaços de ar nos tecidos foi determinada com base na remoção da fase gasosa. A modificação introduzida ao método original referese à substituição do uso de um homogeneizador por trituração da amostra em almofariz.

Firmeza - Foi medida a firmeza dependente da turgidez celular pelo método de aplanação, proposto por Calbo $\&$ Nery (1995). Foram acompanhados 15 frutos de gueroba armazenados a $25^{\circ} \mathrm{C}$, fazendo-se diariamente uma medida por fruto, durante o período de amadurecimento.

A área da elipse aplanada (A) foi calculada com a fórmula: $A=D_{1} \cdot D_{2} \cdot \pi / 4$, onde $D_{1}$ é o diâmetro maior $(\mathrm{cm})$ e $\mathrm{D}_{2}$ é o diâmetro menor $(\mathrm{cm})$ e o número considerado foi de 3,1416. A firmeza (Fz), então, foi calculada dividindo-se o massa da placa de prova $(\mathrm{P})$ em kgf pela área aplanada $(\mathrm{A}) \mathrm{em}^{2} \mathrm{~cm}^{2}$, tendo como resultado a unidade de pressão em $\mathrm{kgf} \mathrm{cm}^{-2}$, com a fórmula: $\mathrm{Fz}=\mathrm{P} / \mathrm{A}$.

Análise estatística - Foi utilizado o software SANEST (Zonta \& Machado 1995). Foi empregada a análise de variância pelo Teste $\mathrm{F}$ e as médias foram comparadas pelo teste de Tukey ao nível de probabilidade de erro de $5 \%$.

\section{Resultados e discussão}

Respiração e evolução de etileno - Nos frutos armazenados em conjunto e individualmente a $25^{\circ} \mathrm{C}$, a evolução de etileno e de $\mathrm{CO}_{2}$ atingiu o valor máximo ao $6^{\circ}$ dia de armazenamento (Fig. 1,2). Os valores no pico foram de $120 \mathrm{ml} \mathrm{kg}^{-1} \mathrm{~h}^{-1} \mathrm{de} \mathrm{CO}_{2}$ e $17 \mu \mathrm{kg}^{-1} \mathrm{~h}^{-1} \mathrm{de}$ etileno para frutos em conjunto e de $98 \mathrm{ml} \mathrm{kg}^{-1} \mathrm{~h}^{-1}$ de $\mathrm{CO}_{2}$ e $12 \mu \mathrm{kg}^{-1} \mathrm{~h}^{-1}$ de etileno para frutos individuais. Em frutos armazenados a $25^{\circ} \mathrm{C}$ a evolução de etileno aumentou entre o verde-maduro e o pico de etileno mais de 12 vezes.

Valores semelhantes foram encontrados em frutos que apresentaram um padrão climatérico com picos de $\mathrm{CO}_{2}$ como por exemplo, frutos de manga (Mangifera indica) mantidos a $20^{\circ} \mathrm{C}\left(130 \mathrm{ml} \mathrm{kg}^{-1} \mathrm{~h}^{-1}\right)$. Esses valores foram superiores, porém, aos de frutos do mamão-papaia (Caryca papaya) que apresentaram um valor de $88 \mathrm{ml} \mathrm{kg}^{-1} \mathrm{~h}^{-1}$ quando mantidos a $25^{\circ} \mathrm{C}$ (Biale et al. 1954).

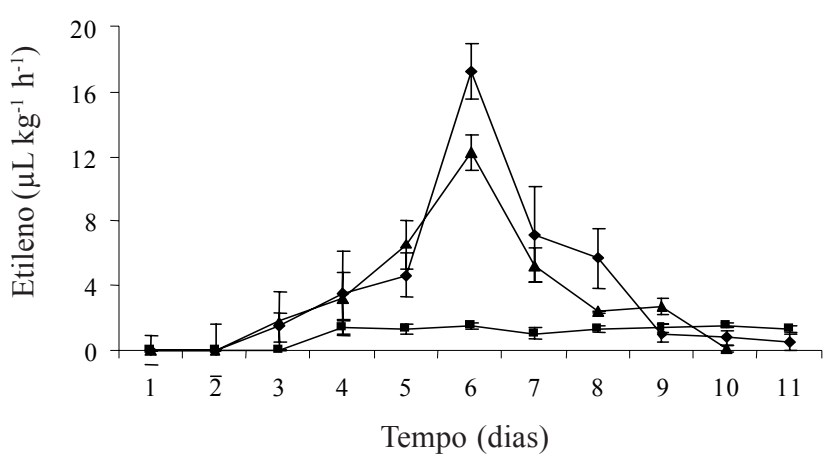

Figura 1. Evolução de etileno $\left(\mu 1 \mathrm{~kg}^{-1} \mathrm{~h}^{-1}\right)$ em frutos de gueroba (Syagrus oleracea (Mart.) Becc.) armazenados em conjunto a $25{ }^{\circ} \mathrm{C}(\bullet)$ e a $8{ }^{\circ} \mathrm{C}(\square)$ e frutos individuais armazenados a $25^{\circ} \mathrm{C}$ $(\boldsymbol{\Delta})$. As barras representam o erro padrão das médias.

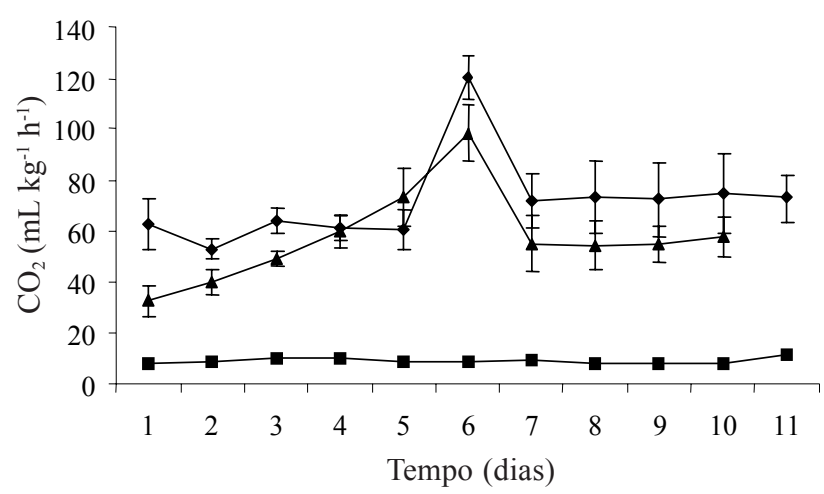

Figura 2. Evolução de $\mathrm{CO}_{2}\left(\mathrm{ml} \mathrm{kg}^{-1} \mathrm{~h}^{-1}\right)$ em frutos de gueroba (Syagrus oleracea (Mart.) Becc.) armazenados em conjunto a $25^{\circ} \mathrm{C}(\bullet)$ e a $8{ }^{\circ} \mathrm{C}(\boldsymbol{\square})$ e frutos individuais armazenados a $25^{\circ} \mathrm{C}$ $(\boldsymbol{\Lambda})$. As barras representam o erro padrão das médias.

No que diz respeito à produção de etileno, podese comparar os frutos de gueroba com frutos de maçãs (Malus sp.) que têm valores de referência de 0,02 a $100 \mu \mathrm{kg}^{-1} \mathrm{~h}^{-1}$, segundo Burg \& Thimann (1960). Nos frutos armazenados em conjunto a $8{ }^{\circ} \mathrm{C}$, a evolução de $\mathrm{CO}_{2}$ e de etileno foi muito menor, sem produção de picos, sendo que a evolução de $\mathrm{CO}_{2}$ variou entre $7 \mathrm{e}$ $11 \mathrm{ml} \mathrm{kg}^{-1} \mathrm{~h}^{-1} \mathrm{e}$ a de etileno, entre 1,0 e $1,5 \mu \mathrm{kg}^{-1} \mathrm{~h}^{-1}$ (Fig. 1, 2).

Houve diferença significativa entre o tratamento com frio a $8{ }^{\circ} \mathrm{C}$ e os demais tratamentos, tanto na evolução de $\mathrm{CO}_{2}$ quanto na de etileno. Essa diferença 
foi marcante, sendo que os frutos que foram armazenados a $8^{\circ} \mathrm{C}$ apresentaram uma evolução, tanto de $\mathrm{CO}_{2}$ quanto de etileno, sem o aparecimento de picos contrastante com os demais tratamentos ao longo do processo de armazenamento. Houve uma correlação positiva entre a produção de etileno e de $\mathrm{CO}_{2}$, ou seja, as evoluções avaliadas tiveram um padrão semelhante.

A $25{ }^{\circ} \mathrm{C}$, observou-se ao longo do período de armazenamento o amadurecimento e amolecimento dos frutos, seguidos de senescência e deterioração. A $8{ }^{\circ} \mathrm{C}$, os frutos apresentaram sinais de injúrias por resfriamento, como coloração amarronzada, pontos pretos na superfície externa e no interior a partir do $8^{\circ}$ dia de armazenamento. Não ocorreu também o amadurecimento e amaciamento dos frutos. Sugere-se que pelo fato dos frutos terem sido mantidos por um período de tempo superior a uma semana, expostos a temperatura baixa, estes tenham começado a apresentar os sintomas de injúria por resfriamento antes mesmo de terem sido retirados da condição de frio. Segundo Wang (2002), em geral os frutos que apresentam esse tipo de injúria mantêm-se com aparência praticamente inalterada quando mantidos a baixas temperaturas e somente percebem-se sinais de injúria por resfriamento ("chilling") quando são expostos a temperaturas mais altas. No caso da gueroba, os frutos apresentaram sinais de injúrias ainda sob a condição de temperatura reduzida.

Os sintomas de injúria por resfriamento, observados em frutos de gueroba, são similares aos descritos por Hardenburg et al. (1986); Pesis et al. (2002) e Wang (2002), e são de ocorrência comum em frutos de origem tropical. Wang (2002) coloca como temperatura segura para a maioria dos frutos tropicais, dentre os quais a banana (Musa sp.), o maracujá (Passiflora sp.), a fruta-pão (Artacarpus altilis), alguns cultivares de abacate (Persea americana) e a manga (Mangifera indica), o patamar mínimo de $10{ }^{\circ} \mathrm{C}$. Valores inferiores a estes, de maneira geral, dão origem a injúrias de resfriamento.

A perda de massa dos frutos de gueroba (Fig. 3) foi gradual nos três tratamentos. Para os frutos armazenados em conjunto (seis frutos com massa média igual a $162 \mathrm{~g}$ ) a $25{ }^{\circ} \mathrm{C}$ esta foi em média de $3 \mathrm{~g} \mathrm{dia}^{-1}$. Em frutos individuais, armazenados a $25^{\circ} \mathrm{C}$, a perda média de massa foi de $0,8 \mathrm{~g} \mathrm{dia}^{-1}$. Em frutos de gueroba em conjunto (seis frutos) a $8{ }^{\circ} \mathrm{C}$ a média diária de perda de massa foi de $2 \mathrm{~g} \mathrm{dia}^{-1}$. A média dos frutos armazenados a $25^{\circ} \mathrm{C}$ apresentou forte queda no último dia, devido ao descarte de frutos que já se encontravam em deterioração, tanto para frutos armazenados em conjunto quanto para frutos individuais. Os frutos armazenados em conjunto a $25^{\circ} \mathrm{C}$ perderam até o $10^{\circ}$ dia aproximadamente $20 \%$ de sua massa inicial ou cerca de $17,3 \mathrm{~g} \mathrm{~kg}^{-1} \mathrm{dia}^{-1}$; valores semelhantes foram observados para frutos individuais. Os frutos armazenados a $8{ }^{\circ} \mathrm{C}$ perderam $17 \%$ de sua massa inicial ou ao redor de $17 \mathrm{~g} \mathrm{~kg}^{-1} \mathrm{dia}^{-1}$.

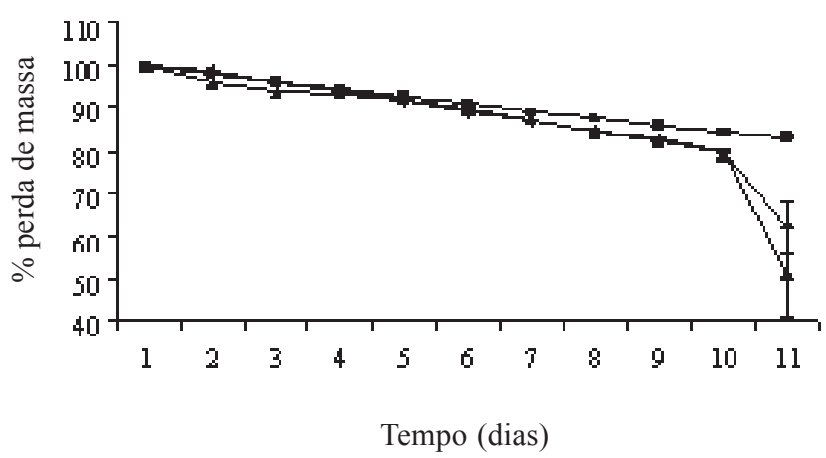

Figura 3. Porcentagem de perda de massa de seis frutos de gueroba (Syagrus oleracea (Mart.) Becc.) armazenados em conjunto a $25^{\circ} \mathrm{C}(\bullet)$ e a $8{ }^{\circ} \mathrm{C}(\boldsymbol{\square})$ e frutos individuais armazenados a $25^{\circ} \mathrm{C}$ $(\boldsymbol{\Delta})$. As barras representam o erro padrão das médias.

A perda de massa a $8{ }^{\circ} \mathrm{C}$ poderia ter sido bem menor, porém a umidade relativa na câmara foi em média de $85 \%$ ao longo do período de armazenamento e a ventilação possivelmente foi maior do que na câmara a $25^{\circ} \mathrm{C}$. De maneira geral, sob condições semelhantes de UR e ventilação, um órgão como um fruto perde água mais rapidamente a temperaturas mais elevadas (Pantastico 1975).

Atmosfera interna - A concentração interna de $\mathrm{O}_{2} \mathrm{e}$ $\mathrm{CO}_{2}$ variou em função do tempo e pôde-se verificar as mudanças ocorridas na atmosfera interna do fruto da gueroba ao longo do amadurecimento (Fig. 4). No caso do $\mathrm{O}_{2}$, parte-se de valores ao redor de $15 \%$ no primeiro dia e tem-se um decréscimo até que seja atingido um mínimo de 12 e $12,3 \%$ no quinto e sexto dias, respectivamente, voltando novamente ao patamar inicial em torno dos 15\% nos dias subseqüentes. Esses valores se aproximam de frutos como a maçã (Malus sp.) que chega a ter $16,4 \%$ de $\mathrm{O}_{2}$ na atmosfera interna, ou mesmo de tubérculos, como a batata (Solanum tuberosum) armazenada, segundo Burton (1982).

Com o $\mathrm{CO}_{2}$ ocorre o oposto, parte-se de valores tão baixos quanto $5,5 \%$ e, no quinto e sexto dias, têm-se um ponto de máximo entre 9 e $10 \%$ de $\mathrm{CO}_{2}$. Logo após, a concentração de $\mathrm{CO}_{2}$ retorna a valores em torno de 5\%. Estes valores são próximos dos citados por Burton (1982) para maçãs (Malus sp.), entre 2,7 


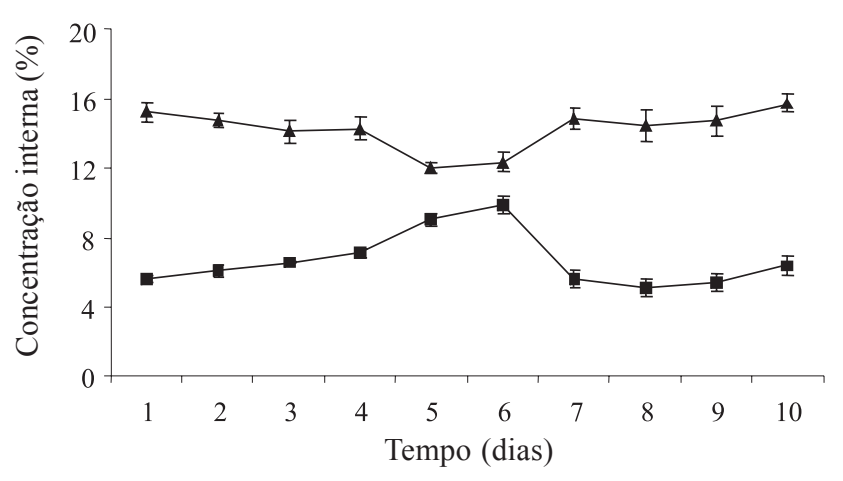

Figura 4. Concentração interna de $\mathrm{O}_{2}(\boldsymbol{\Delta})$ e $\mathrm{CO}_{2}(\boldsymbol{\square})$ (porcentagem) em frutos de gueroba (Syagrus oleracea (Mart.) Becc.) armazenados a $25^{\circ} \mathrm{C}$ durante o processo de amadurecimento. As barras representam o erro padrão das médias.

e 5,6\%, ou mesmo para maracujá (Passiflora sp.), cerca de $7 \%$ de $\mathrm{CO}_{2}$

Com o auxílio da análise estatística, foi possível identificar uma correlação negativa entre $\mathrm{CO}_{2}$ e $\mathrm{O}_{2}$. Isto significa que estes dois fatores foram, durante $\mathrm{o}$ período de armazenamento dos frutos da gueroba, inversamente proporcionais: à medida que a concentração interna de $\mathrm{CO}_{2}$ aumentava, a de $\mathrm{O}_{2}$ diminuía. Isto se deve ao fato de que o fruto continua a realizar diversos processos para a sua manutenção, como por exemplo a respiração, em que ocorre o consumo de $\mathrm{O}_{2}$ e a liberação de $\mathrm{CO}_{2}$.

O padrão observado era esperado e condiz com outros encontrados na literatura como, por exemplo, em melões (Cucumis melo) (Lyons et al. 1964) e em abacate (Persea americana) (Biale 1964).

Os valores observados para o $\mathrm{CO}_{2}$ na atmosfera interna estão de acordo com os valores de evolução de $\mathrm{CO}_{2}$ ao longo do processo de armazenamento dos frutos à temperatura ambiente. Houve uma simultaneidade, uma correlação positiva, na variação da concentração interna (Fig. 4) e na evolução de $\mathrm{CO}_{2}$ (Fig. 2), o que é evidência do padrão climatérico de respiração no fruto da gueroba. Na medida em que o fruto respira e produz $\mathrm{CO}_{2}$, este se difunde para o ar exterior, contribuindo para a evolução desse gás de maneira diretamente proporcional.

A observação dos padrões de concentração de $\mathrm{O}_{2}$ e $\mathrm{CO}_{2}$ na atmosfera interna (Fig. 4) são consistentes com os padrões de evolução de etileno (Fig. 1) e de $\mathrm{CO}_{2}$ (Fig. 2) e reforçam a noção de que a gueroba realmente seja um fruto climatérico. $\mathrm{O}$ fato da evolução de etileno ter aumentado mais de 12 vezes entre o verde-maduro e o pico de etileno é um fator que reforça essa afirmativa.
A constante de conversão de $\mathrm{CO}_{2}$ para a gueroba foi de 0,96. Com este valor, pode-se estimar a concentração interna de $\mathrm{CO}_{2}$, conhecendo-se a sua taxa de produção, ou estimar a sua produção, pela concentração interna de $\mathrm{CO}_{2}$.

Volumes gasosos intercelulares - $\mathrm{O}$ volume médio de espaços gasosos intercelulares do fruto da gueroba foi de $5,18 \%$, sendo que a polpa representa cerca de $61 \%$ desse valor, enquanto a semente, mais rígida e menos porosa, perfaz $39 \%$ do total. O valor obtido para os volumes gasosos intercelulares da gueroba colocam os seus frutos dentro da faixa de órgãos com quantidade média de volumes gasosos, como, por exemplo, a batata doce (Ipomea batatas) e a goiaba (Psidium guajava). Segundo Crisosto (2004), esta quantidade média de volumes gasosos está relacionada a uma resistência relativa a injúrias de impacto e a uma susceptibilidade moderada a injúrias de amassamento durante o armazenamento e o transporte.

Firmeza - Foi observada a redução da firmeza dos frutos em função do tempo de armazenamento (Fig. 5). A diminuição da firmeza foi gradual ao longo de todo o processo de amadurecimento. A firmeza dependente da turgidez celular apresentou inicialmente níveis ao redor de $0,35 \mathrm{kgf} \mathrm{cm}^{-2}$. Os frutos nos primeiros dias após a colheita suportavam a carga de peso sem apresentar deformações, apresentando apenas marcas reversíveis. Com o passar dos dias a sua resistência foi diminuindo e chegou-se ao fim do experimento a valores mais baixos que $0,1 \mathrm{kgf} \mathrm{cm}^{-2}$, em que os frutos passaram a apresentar pequenas fissuras quando submetidos ao método e apresentaram também deformações irreversíveis.

A firmeza inicial dos frutos da gueroba $\left(0,35 \mathrm{kgf} \mathrm{cm}^{-2}\right)$ é da mesma ordem, porém ligeiramente

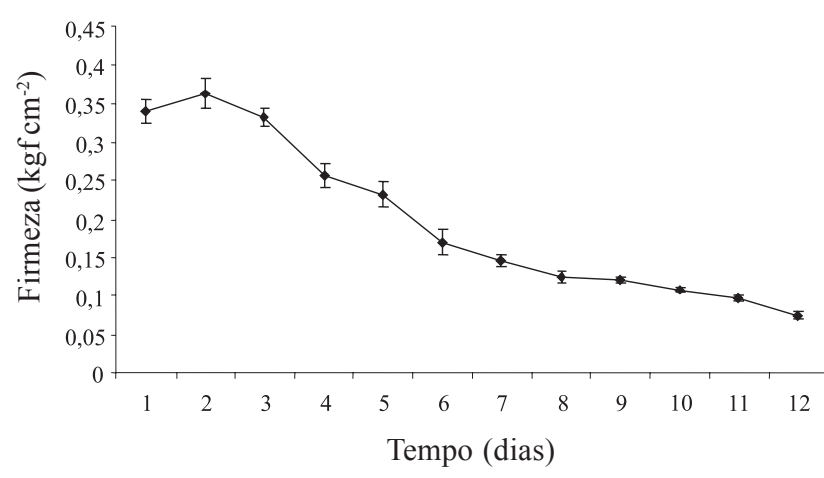

Figura 5. Mudança na firmeza dependente da turgidez celular, em $\mathrm{kgf} \mathrm{cm}^{-2}$, durante o amadurecimento dos frutos da gueroba (Syagrus oleracea (Mart.) Becc.) armazenados a $25^{\circ} \mathrm{C}$. As barras representam o erro padrão das médias. 
menor do que a firmeza de alguns outros frutos relatados na literatura, tais como tomate meio maduro (Lycopersicon esculentum), mamão (Caryca papaya), jiló (Solanum gilo) e uva (Vitis vinifera) (Luengo \& Calbo 2001). O decréscimo da firmeza dependente do turgor celular no tempo, no entanto, foi bem maior que para outros frutos estudados, como tomate (Lycopersicon esculentum) (Freitas et al. 1999) e mamão (Jacomino et al. 2002).

Os frutos da gueroba (Syagrus oleracea) são sensíveis à injúria de resfriamento e quando armazenados à temperatura de $8^{\circ} \mathrm{C}$ apresentam sinais de injúria pelo frio e não amadurecem mesmo quando recolocados à temperatura ambiente.

Os picos de evolução de etileno e $\mathrm{CO}_{2}$ ocorreram de maneira coincidente no sexto dia de armazenamento.

Nos frutos de gueroba (Syagrus oleracea) as curvas de concentração de $\mathrm{CO}_{2}$ e $\mathrm{O}_{2}$ na atmosfera interna, também são evidências de que se trata de um fruto climatérico.

O valor obtido para os volumes gasosos intercelulares dos frutos da gueroba coloca-os dentro da faixa de órgãos com média quantidade de volumes gasosos, média susceptibilidade à injúria de impacto e média susceptibilidade a injúrias de amassamento.

\section{Referências bibliográficas}

Biale, J.B. 1964. Growth, maturation, and senescence in fruits. Science 146: 880-888.

Biale, J.B.; Young, R.E. \& Olmstead, A.J. 1954. Fruit respiration and ethylene production. Plant Physiology 29: $168-174$.

Burg, S.P. \& Thimann, K.V. 1960. Studies on ethylene production of apple tissue. Plant Physiology 35: 24-35.

Burton, W.G. 1982. Physiology of food crops. New York, Longman.

Calbo, A.G. 2004. FACILI: uma adaptação eudimétrica para medir $\mathrm{CO}_{2}$ e $\mathrm{O}_{2}$ de microamostras de atmosferas modificas e controladas Embrapa-Hortaliças URL: http:// www.cnph.embrapa.br/laborato/pos_colheita/ faciliti.htm. (Acesso: 29/09/2004).

Calbo, A.G. \& Nery, A.A. 1995. Medida de firmeza de hortaliças pela técnica de aplanação. Horticultura Brasileira 13: 14-18.

Calbo, M.E.R. \& Miranda, G.G. 1991. Estudos pós-colheita de frutos de pequi. III Congresso Brasileiro de Fisiologia Vegetal. Viçosa. Resumos.
Calbo, M.E.R.; Lima, J.N. \& Calbo, A.G. 1990. Fisiologia póscolheita de frutos de cagaita. Revista Brasileira de Fisiologia Vegetal 2: 15-18.

Correa, M. Pio. 1931. Dicionário de Plantas Úteis do Brasil. Ministério da Agricultura. Rio de Janeiro, Imprensa Nacional.

Crisosto, C.H. 2004. Handling preconditioned tree fruit at the retail distribution centers. Central Valley Postharvest Newsletter 13: 1-3.

Freitas, J.A.; Maluf, W.R.; Gomes, L.A.A. \& Azevedo, S.M. 1999. Efeitos dos alelos alc $o g^{c}$ e $h p$ sobre as características de maturação e conservação pós-colheita de frutos de tomateiro. Ciência e Agrotecnia 23: 569-577.

Hardenburg, R.E.; Watada, A.E. \& Wang, C.Y. 1986. The commercial storage of Fruits, Vegetables, and Florist and Nursery Stocks Agriculture Handbook N. 66. Davis, U.S. Department of Agriculture.

Henderson, A.; Galeano, G. \& Bernal, R. 1995. Field Guide to the Palms of the Americas. New Jersey, Princeton University Press.

Jacomino, A.P.; Kluge, R.A.; Brackmann. A. \& Castro, P.R.C. 2002. Amadurecimento e senescência de mamão com 1-metilciclopropeno. Scientia Agricola 59: 303-308.

Jensen, C.R.; Luxmore, R.J.; Van Grundy, S.D. \& Stolzy, L.H. 1969. Root air space measure by a pycnometer method. Agronomic Journal 61: 474-475.

Lorenzi, H. 1992. Árvores Brasileiras. Nova Odessa, Editora Plantarum.

Lorenzi, H.; Souza, H.M.; Madeiros-Costa, J.T.; Cerqueira, L.S.C. \& Ferreira, E. 2004. Palmeiras Brasileiras e Exóticas Cultivadas. Nova Odessa, Editora Plantarum.

Luengo, R.F.A. \& Calbo, A.G. 2001. Armazenamento de hortaliças. Brasília, Embrapa Hortaliças.

Lyons, J.M. \& Pratt, H.K. 1964. Effect of stage of maturity and ethylene treatment on respiration and ripening of tomato fruits. Proceedings of the American Society of Horticultural Science 84: 491-500.

Pantastico, E.B. 1975. Postharvest physiology, handling and utilization of tropical and subtropical fruits and vegetables. Westport, The AVI Publishing.

Pesis, E.; Ackerman, M.; Ben-Arie, R.; Feygenberg, O.; Feng, X.; Apelbaum, A.; Goren, R. \& Prusky, D. 2002. Ethylene involvement in chilling injury symptoms of avocado during cold storage. Postharvest Biology and Technology 24: 171-181.

Wang, C.Y. 2002. Chilling and Freezing Injury In: K.C. Gross. Agriculture Handbook 66 (HB-66). Beltsville, USDA, ARS.

Zonta, E.P. \& Machado, A.A. 1995. Sistemas de análises estatísticas (SANEST) para microcomputadores. Pp. 17-18. In: Simpósio de Estatística Aplicada à Experimentação. Campinas, Fundação Cargil. 